\title{
Synthesis and characterization of nanocrystalline silicon carbide thin films on multimode fiber optic by means I $50 \mathrm{MHz}$ VHF-PECVD
}

\begin{abstract}
Nanocrystalline Silicon carbide thin films were deposited using $150 \mathrm{MHz}$ very high frequency plasma enhanced chemical vapor deposition (VHF-PECVD) system on the Multimode optical fiber (MMF). The mixture of methane $\left(\mathrm{CH}_{4}\right)$ and silane $\left(\mathrm{SiH}_{4}\right)$ as reactive precursor gases and $\mathrm{H}_{2}$ as a carrier were used. The effects of deposition time on the bonding energy, composition and microstructural characteristics of $\mathrm{SiC}$ thin films were investigated using FTIR, EDS and FE-SEM. The results reveal that the nanocrystalline $\mathrm{SiC}$ films were successfully deposited on the MMF. The thickness of $\mathrm{SiC}$ films increased from $54 \mathrm{~nm}$ to $1.56 \mu \mathrm{m}$ as the deposition time is increased from 1 to 3 minutes. The sensitivity of MMF increased from $1.825 \mathrm{~dB} / \mathrm{UIR}$ to $7.341 \mathrm{~dB} / \mathrm{UIR}$ by the $1 \mathrm{~min}$ deposition time of SiC. Thus, the $150 \mathrm{MHz}$ VHF-PECVD seemed to be a suitable technique for coating nanocrystalline $\mathrm{SiC}$ thin films and enhancing the sensitivity of the MMF.
\end{abstract}

Keywords: VHF-PECVD, Optical fiber sensor, nanocrystalline, SiC, deposition time
Volume 4 Issue I - 2018

\author{
Marwan Hafeedh Younus, ${ }^{1,2}$, Shahrouz Zamani \\ Khalajabadi, ${ }^{3,4}$ Aminudin Bin Haji Abu, ${ }^{3}$ Odai \\ Falah Ameen, ${ }^{1,2}$ Norhayati Ahmad, ${ }^{4}$ Norizah \\ Redzuan, ${ }^{4}$ Raja Kamarulzaman Raja Ibrahim' \\ 'Department of Physics, Universiti Teknologi Malaysia (UTM) \\ Malaysia \\ ${ }^{2}$ Department of Physics, University of Mosul, Iraq \\ ${ }^{3}$ Malaysia-Japan International Institute of Technology (MJIIT), \\ Universiti Teknologi Malaysia (UTM), Malaysia \\ ${ }^{4}$ Department of Material, Manufacturing and Industrial \\ Engineering, Universiti Teknologi Malaysia, Malaysia
}

\author{
Correspondence: Raja Kamarulzaman Raja Ibrahim, \\ Department of Physics, Universiti Teknologi Malaysia (UTM), \\ 8।310 Johor Bahru, Johor, Malaysia, \\ Email rkamarulzaman@utm.my
}

Received: January 28, 2018 | Published: February 21, 2018

Abbreviations: VHF-PECVD, very high frequency plasma enhanced chemical vapor deposition; MMF, multimode optical fiber; $\mathrm{SiC}$, silicon carbide; Si Silicon; HW-CVD, hot wire chemical vapor deposition; RF-PECVD, radio frequency plasma enhanced chemical vapor deposition; OTDR, optical time domain reflectometer; FTIR, fourier-transform infrared; AFM, atomic force microscopy

\section{Introduction}

In recent years, a number of advantages such as modification of nano-crystalline thin films, the ability for low-temperature deposition processes, the controlling of process, as well as high efficiency and repeatability of process, were offered using plasma deposition technique. ${ }^{1}$ Silicon carbide ( $\left.\mathrm{SiC}\right)$ as a leading candidate for the replacement of Silicon (Si) for high-temperature and power electronic devices has attracted more attention due to its mechanical robustness and chemical inertness at elevated temperatures. ${ }^{2,3}$ It also becomes an attractive and promising material for fabricating high-temperature pressure sensors. Furthermore, the wide band gap, a high-breakdown electric field, fast response time, mechanical strength and a low leakage current of $\mathrm{SiC}$ made it a better material than silicon in hightemperature electronic applications. ${ }^{4-8}$ In addition, the semiconductor coating layers such as $\mathrm{SiC}$ and $\mathrm{Si}$ have features apart from sensitivity enhancement of the optical fiber, such as fiber protection, tunability of the resonance wavelength region and bio-chemical compatibility of the sensor., ${ }^{9,10}$ According to a study reported by Kumar et al., ${ }^{3}$ the performance of an optical fiber sensor fabricated using surface plasmon resonance (SPR) technique can be enhanced by using silicon carbide (SiC). Nowadays, the plasma enhanced chemical vapor deposition (PECVD), ${ }^{11-13}$ reactive magnetron sputtering,,${ }^{14}$ hot wire chemical vapor deposition (HW-CVD) $)^{15}$ and radio frequency plasma enhanced chemical vapor deposition (RF-PECVD) systems ${ }^{16}$ are common techniques that are used to grow the nanocrystalline $\mathrm{SiC}$ films. PECVD is the most widely used method for the growth of the $\mathrm{SiC}$ thin films because of its lower working temperature compared to the other techniques.

Over the decade, a different range of plasma excitation frequencies has been developed to determine the optimum condition to synthesize high quality thin films of nanocrystalline $\mathrm{SiC}$ with using PECVD. These researches were more focused on the application of low, medium and high frequencies such as $13.56 \mathrm{MHz}, 27.12 \mathrm{MHz}$ and $60 \mathrm{MHz} .{ }^{6,16-19}$ According to the author's knowledge, the use of a very high frequency (VHF) PECVD at $150 \mathrm{MHz}$ to grow nanocrystalline $\mathrm{SiC}$ films on the multimode optical fiber (MMF) has not been reported elsewhere. In this paper, the growth of the nanocrystalline $\mathrm{SiC}$ thin films on the MMF using VHF-PECVD at $150 \mathrm{MHz}$ excitation frequency was performed. The effect of various deposition times on the microstructure, thickness and homogeneity of $\mathrm{SiC}$ thin films on the MMF was investigated using FE-SEM. The elemental analysis, composition, and the bond structure of the deposited $\mathrm{SiC}$ films were studied using EDS and FTIR. The sensitivity of MMF was measured by the Optical Time Domain Reflectometer (OTDR) technique.

\section{Materials and methods}

The SiC films were deposited on the MMF using a VHF-PECVD system at a substrate temperature of $25^{\circ} \mathrm{C}$. The plasma-excitation frequency of the system was $150 \mathrm{MHz}$. Silane $\left(\mathrm{SiH}_{4}, 99.9995 \%\right)$ and methane $\left(\mathrm{CH}_{4}, 99.999 \%\right)$ gases were used as reactive precursor gases for $\mathrm{SiC}$ thin films deposition, while the carrier gas was the hydrogen $\left(\mathrm{H}_{2}, 99.999 \%\right)$. The $\mathrm{SiH}_{4}$ flow rate was adjusted at $2 \mathrm{sccm}$, the $\mathrm{CH}_{4}$ flow rate at $20 \mathrm{sccm}, \mathrm{H}_{2}$ flow rate at $25 \mathrm{sccm}$, total pressure at $9 \times 10^{-}$ 
${ }^{2}$ Tor and plasma power density at $20 \mathrm{~W}$. The deposition times were fixed at 1, 2 and 3 minutes. A Perkin Elmer (SP8000, UK) Fouriertransform infrared (FTIR) spectrometer was used to determine the functional groups of the deposited films. The surface morphology, the film thickness and cross-section images of the deposited SiC films were observed using a field emission scanning electron microscopy (FE-SEM JEOL JSM-5800 LV) equipped with an energy dispersive (EDS) X-ray spectrometer. The elemental analysis of the deposited films was performed using EDS. The surface topography and roughness of the deposited $\mathrm{SiC}$ films by $150 \mathrm{MHz}$ VHF-PECVD were examined by Atomic Force microscopy (AFM). The Optical Time Domain Reflectometer (OTDR) technique was introduced to measure the return loss of the MMF sensor with and without the $\mathrm{SiC}$ coating. The sensitivity in term of the return loss per unit of refractive index $(\mathrm{dB} / \mathrm{UIR})$ of the MMF was determined with different refractive indices ranging from 1.440-1.474 of pure liquid Cargille solutions.

\section{Results and discussion}

Figure 1 displays the typical EDS spectra of MMF before and after $\mathrm{SiC}$ deposition. It shows that the $\mathrm{Si}, \mathrm{C}$ and $\mathrm{O}$ elements are detected after different deposition times. The EDS results of the SiC films deposited at 1,2 and 3 minutes are mainly composed of Si, C and $\mathrm{O}$ (Figure 1B-1D), while the EDS spectra of MMF without SiC is composed of only $\mathrm{Si}$ and $\mathrm{O}$ as shown in Figure 1A. It should be noted that the EDS detection of the $\mathrm{C}$ spectra as well as the decrease of in the $\mathrm{O}$ intensity confirm the substantial growth of $\mathrm{SiC}$ films on MMFs. Figure 2B shows the elemental mapping of MMF before and after $1 \mathrm{~min}$ of $\mathrm{SiC}$ deposition. The synthesis of $\mathrm{SiC}$ film with uniform thickness can be observed in Figure 2B. As can be seen in Figure 2A, there is no $\mathrm{C}$ element on the surface of MMF before $\mathrm{SiC}$ deposition. Images (a), (c), and (e) in Figure 3 present the cross section of the MMF sensor coated with $\mathrm{SiC}$ film at different deposition times of 1 , 2 , and 3 minutes, respectively. Images (b), (d), and (f) in Figure 3 present the surface morphologies of MMF sensor coated with $\mathrm{SiC}$ film at deposition time of 1,2 , and 3 minutes, respectively. It can be seen that a continuous and uniform film of $\mathrm{SiC}$ is deposited on the MMF using $150 \mathrm{MHz}$ VHF-PECVD (Figure 3A \& Figure 3C Figure\& 3E). The FE-SEM images reveal the dependent of morphology of the SiC film on the deposition time. As shown in Figure 3A, at the deposition time of 1 minute, the thin film of $\mathrm{SiC}$ is created and covered the entire cross section of MMF sensor with thickness of 54.06nm.
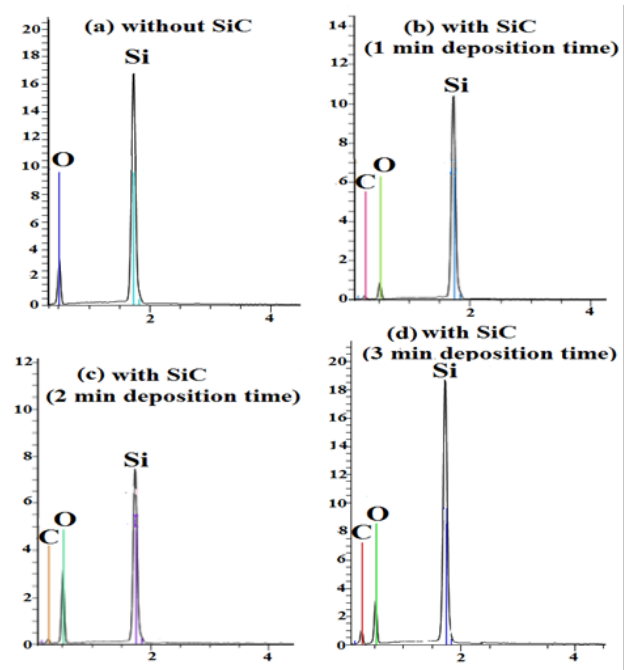

Figure I EDS analysis of MMFs without $\mathrm{SiC}$ coating and after various deposition time of $\mathrm{SiC}$

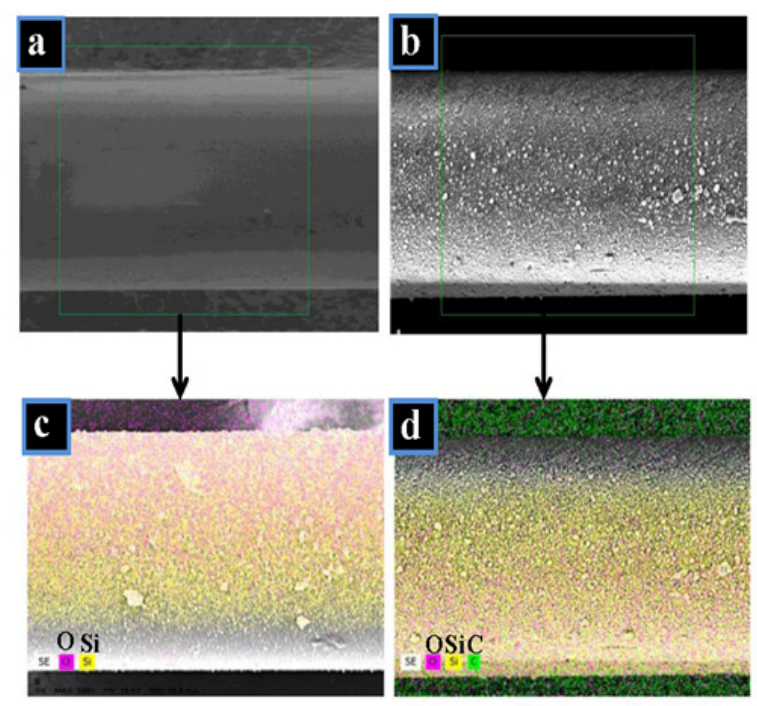

Figure 2 X-ray elemental mapping of MMF (A) without $\mathrm{SiC}(\mathrm{B})$ I min deposition of SiC. FESEM images of MMF (C) without SiC and (D) after I min deposition time

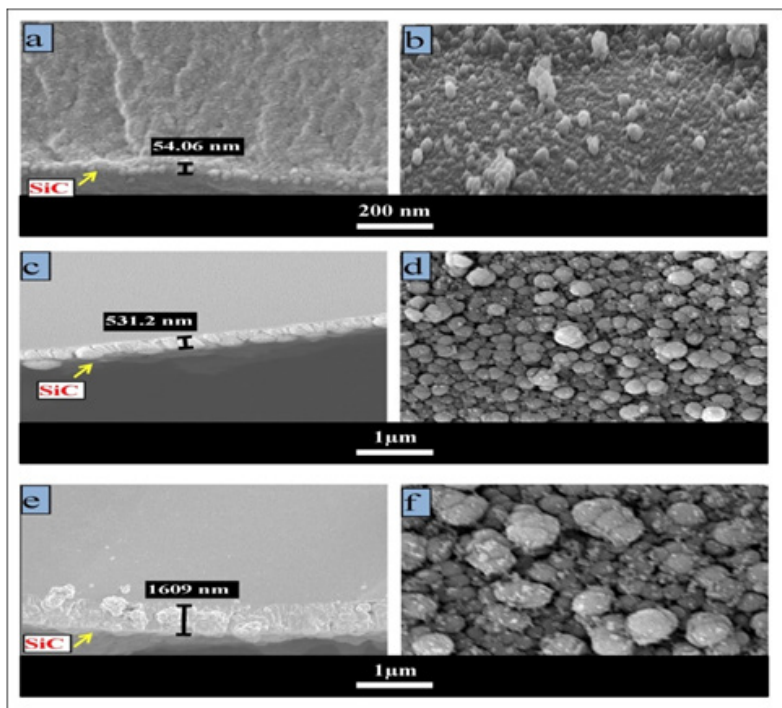

Figure 3 Cross-section FESEM micrographs of $\mathrm{SiC}$ coated MMFs for various deposition times: (A) I min, (C) 2 minutes and (E) 3 minutes. Surface FESEM micrographs of $\mathrm{SiC}$ coated MMFs for various deposition times: (B) I min, (D) 2 minutes and (F) 3 minutes

Figure 3B depicts the smooth surface morphology of the SiC film consisting nanoparticles with $\sim 30 \mathrm{~nm}$ particle size that deposited on the MMF sensor at 1 minute deposition time. The extension of the deposition time to 2 and 3 minutes increase the thickness of the deposited $\mathrm{SiC}$ films to $531.2 \mathrm{~nm}$ and $1609 \mathrm{~nm}$ (Figure 3C \& Figure $3 \mathrm{E})$, respectively. The surface of the $\mathrm{SiC}$ film becomes rough as the number of $\mathrm{SiC}$ granules has increased. By increasing deposition time, the small nanoparticles of $\mathrm{SiC}$ films tend to form agglomerates that reduced the homogeneity of particle size of the deposited films as shown in Figure 3D and f. However, the porosity of the particles deposited films also decreased with increasing deposition time, and as a result, the $\mathrm{SiC}$ films become more compact. It can be concluded that the $\mathrm{SiC}$ film at deposition time of 1 minute is very smooth and thin that almost covered the whole length of the MMF sensor which can be useful to enhance the sensitivity of the MMF. Whereas, the thicker $\mathrm{SiC}$ films at deposition time of 2 and 3 minutes has a strong tendency 
to form agglomerates, which can affect the performance of the MMF sensor. Figure 4 shows the high-resolution AFM images of the surface topography for the MMF sensor with and without $\mathrm{SiC}$ at scanning area size $\left(5 X 5 \mu \mathrm{m}^{2}\right)$. Figure $4 \mathrm{~A}$ shows the MMF without $\mathrm{SiC}$ with average surface roughness $\mathrm{R}_{\mathrm{rms}}=1.13039 \mathrm{~nm}$. Image in Figure $4 \mathrm{~b}$ shows the deposited $\mathrm{SiC}$ film on the MMF at $1 \mathrm{~min}$ deposition time with average roughness surface $R_{r m s}=2.76005 \mathrm{~nm}$ while image in Figure $4 \mathrm{c}$ shows the deposited $\mathrm{SiC}$ on the MMF at 3 min deposition time with average roughness $R_{\mathrm{rms}}=15.535 \mathrm{~nm}$. It can notice that the roughness of $\mathrm{SiC}$ surface is increases as the deposition time is extended. Furthermore, the surface microstructure of $\mathrm{SiC}$ is spherical which supports the results that obtained from the FE-SEM image; however, the crosssectional images show the columnar growth of $\mathrm{SiC}$ particles in nanoscale were obtained using $150 \mathrm{MHz}$ VHF-PECVD.
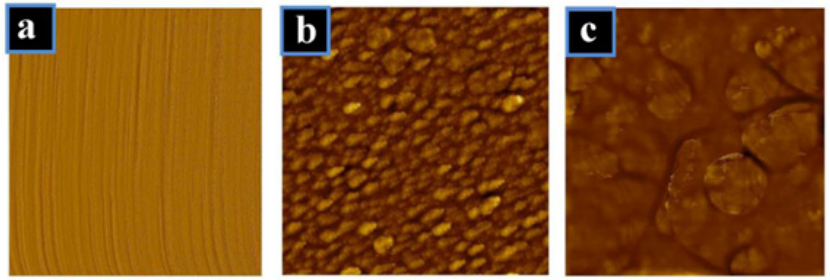

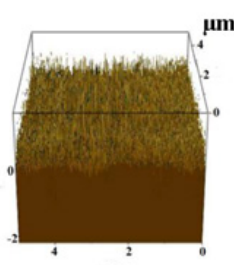

$\mu \mathrm{m}$

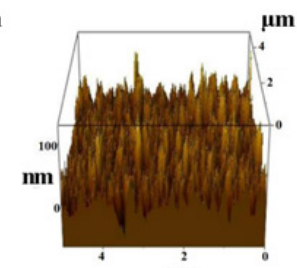

$\mu \mathrm{m}$

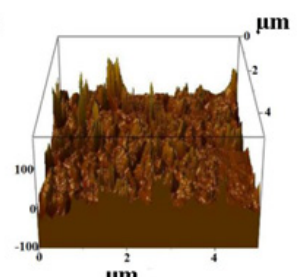

$\mu \mathrm{m}$
Figure 4 The surface AFM and 3D-AFM images of the MMF after SiC deposition using I50MHzVHF-PECVD technique (A) without SiC coating , (B) I min and (C) 3 min of deposition time

Figure 5A shows the FTIR absorption spectrum of the MMF sensor before and after the $\mathrm{SiC}$ deposition. The peak at $800 \mathrm{~cm}^{-1}$ is assigned to $\mathrm{SiC}$ bond. ${ }^{20-22}$ The presence of $\mathrm{SiC}$ bond clearly confirms the formation of $\mathrm{SiC}$ film on the MMF sensor. Figure 5B illustrates only the $\mathrm{SiC}$ spectra, which clearly shows that by increasing of deposition time, the intensity of $\mathrm{SiC}$ peak also increased indicating the increasing amount of deposited $\mathrm{SiC}$ films. The peak at $930-1000 \mathrm{~cm}^{-1}$ is due to the wagging and vibration mode of the $\mathrm{C}-\mathrm{H}$ bond. ${ }^{21}$ FTIR band at $\sim 1210 \mathrm{~cm}^{-1}$ represents the vibration mode of the Si-O bond, ${ }^{21,23}$ The peaks at 1335 and $1424 \mathrm{~cm}^{-1}$ are the symmetric modes of the $\mathrm{C}-\mathrm{H} 3$ and $\mathrm{Si}-\mathrm{O}$ absorption bands, respectively. ${ }^{24,25}$ The Raman analysis also indicates the formation $\mathrm{SiC}$ films by $150 \mathrm{MHz}$ VHF-PECVD method (Figure 6), as the spectra are appeared at $766 \mathrm{~cm}^{-1}$ and $976 \mathrm{~cm}^{-1}$ wave numbers that represent presence $\mathrm{SiC}$ films on the surface MMFs. Increase of intensity of Raman spectra at longer deposition times describes the synthesis of larger amount of $\mathrm{SiC}$. These results are consistent with FTIR spectroscopy analysis. Figure 7 shows the return loss of MMF sensor with and without $\mathrm{SiC}$ coating versus different refractive indices of the Cargille solutions. The MMF coated SiC shows the higher return loss than the uncoated MMF that indicates the increase in sensitivity of $\mathrm{SiC}$ coated MMF. The maximum values of sensitivity of MMF without and with $\mathrm{SiC}$ (i.e. return loss per unit change in refractive index) were found to be $1.825 \mathrm{~dB} / \mathrm{UIR}$ and 7 . $341 \mathrm{~dB} / \mathrm{UIR}$, respectively. Overall, results show that the interactions of different refractive index of the Cargille solutions with $\mathrm{SiC}$ films make the sensor highly sensitive when compared to the uncoated MMF.

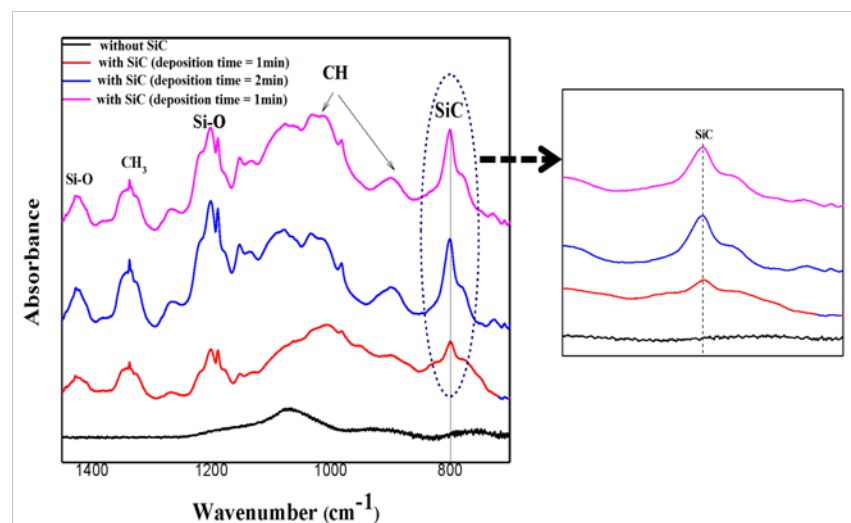

Figure 5 FTIR absorption spectra of MMF before and after various deposition time of $\mathrm{SiC}$ coating.

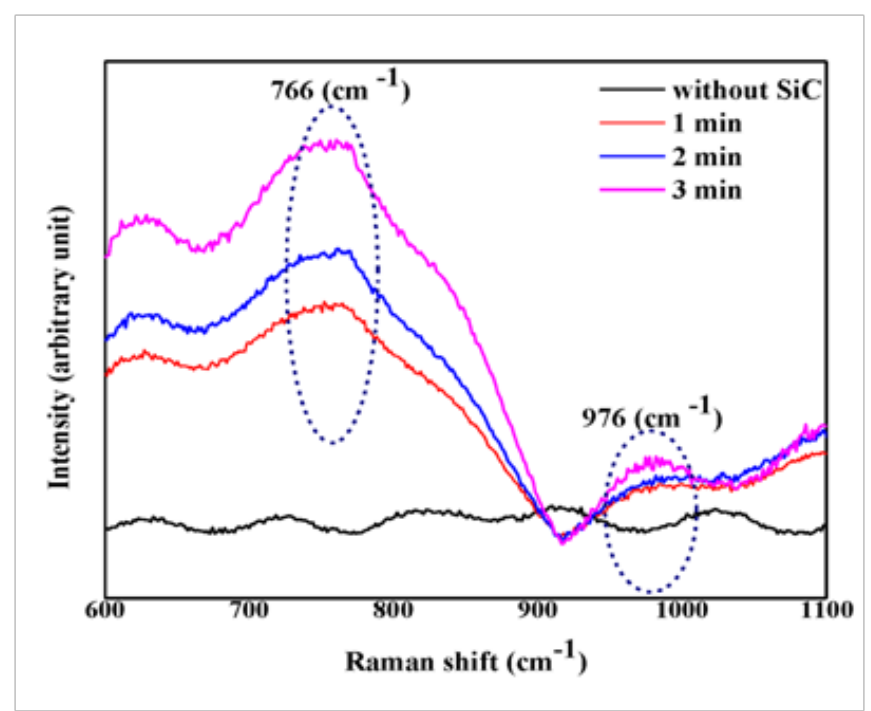

Figure 6 Raman spectra of the MMF sensor with the SiC for different deposition times using I 50MHz VHF-PECVD technique.

\section{Conclusion}

Referring back to the FTIR, EDS and RAMAN analysis as well as FE-SEM and AFM images, it can be deduced that the SiC films were successfully deposited on the surface of MMF using $150 \mathrm{MHz}$ VHFPECVD. However, increasing deposition time would also increase the amount of $\mathrm{SiC}$ coating and the number of $\mathrm{SiC}$ agglomerates. The sensitivity of MMF was found to significantly increase by the $1 \mathrm{~min}$ $\mathrm{SiC}$ deposition.

\section{Acknowledgements}

The authors want to thank and appreciate the staff at the Laser Center, University Technology Malaysia (UTM) for providing research facilities required to complete this study. The authors gratefully acknowledge for financial support research of Grant No. 4F648 as well as the contract research Grant No. R.J130000.7826.4F869, Q.J130000.2526.13H67.

\section{Conflict of interest}

The author declares no conflict of interest. 


\section{References}

1. Dominik M, Koba M, Bogdanowicz R, et al. Plasma-based deposition and processing techniques for optical fiber sensing. Fiber Optic Sensors. 2017. p. $95-114$.

2. Tomastik C, JM Lackner, Pauschitz A, et al. Structural, chemical and nanomechanical investigations of $\mathrm{SiC} /$ polymeric a-C: $\mathrm{H}$ films deposited by reactive RF unbalanced magnetron sputtering. Solid State Sciences. 2016;53:1-8.

3. Li GY, Li XD, Wang H, et al. Ultra long SiC nanowires with fluctuating diameters synthesized in a polymer pyrolysis CVD route. Solid State Sciences. 2009; 11(12):2167-2172.

4. Koh J, Lu Y, Kim S, et al. Real time spectroscopic ellipsometry study of hydrogenated amorphous silicon $p-i-n$ solar cells: Characterization of microstructural evolution and optical gaps. Appl Phys Lett. 1995;67(18):2669-2671.

5. Mehregany M, Zorman CA, Rajan N, et al. Silicon carbide MEMS for harsh environments. Proceedings of the IEEE. 1998;86(8):1594-1609.

6. Liu L, Tang W, Zheng BX, et al. Fabrication and characterization of SiC thin films. IEEE; 2011. p. 146-149.

7. Kim S, Choi J, Jung M, et al. Silicon carbide-based hydrogen gas sensors for high-temperature applications. Sensors (Basel). 2013;13(10):1357513583.

8. Sanger A, Jain PK, Mishra YK, et al. Palladium decorated silicon carbide nanocauliflowers for hydrogen gas sensing application. Sensor and Actuators B: Chemical. 2017;242:694-699.

9. Bhatia P, Gupta BD. Surface plasmon resonance based fiber optic refractive index sensor utilizing silicon layer: effect of doping. Optics Communications. 2013;286:171-175.

10. Spann BT, Compton R, Ratchford D, et al. Photoinduced tunability of the reststrahlen band in 4H-SiC. Physical Review B. 2016;93(8):085205.

11. Daves W, Krauss A, Behnel N, et al. Amorphous silicon carbide thin films (a-SiC: $\mathrm{H}$ ) deposited by plasma-enhanced chemical vapor deposition as protective coatings for harsh environment applications. Thin Solid Films. 2011;519(18):5892-5898.

12. Peter S, Bernütz S, Berg S, Richter F. FTIR analysis of a-SiCN: H films deposited by PECVD. Vacuum. 2013;98:81-87.

13. Peter S, Günther M, Berg S, et al. Mid-frequency PECVD of a-SiCN: H films and their structural, mechanical and electrical properties. Vacuum. 2013;90:155-159.

14. Daouahi M, Rekik N. Effect of Substrate Temperature on (Micro/ Nano) Structure of a-SiC: H Thin Films Deposited by Radio-Frequency Magnetron Sputtering. J Phys Chem C. 2012;116(39):21018-21026.
15. Swain BP. The analysis of carbon bonding environment in HWCVD deposited a-SiC: H films by XPS and Raman spectroscopy. Surface and Coating Technology. 2006;201(3):1589-1593.

16. Chen E, Du G, Zhang Y, et al. RF-PECVD deposition and optical properties of hydrogenated amorphous silicon carbide thin films. Ceramics International. 2014;40(7):9791-9797.

17. Zhang S, Raniero L, Fortunato E, et al. Characterization of silicon carbide thin films prepared by VHF-PECVD technology. $J$ Non-Cryst Solids. 2004;338:530-533

18. Yunaz IA, Hashizume K, Miyajima S, et al. Fabrication of amorphous silicon carbide films using VHF-PECVD for triple-junction thin-film solar cell applications. Sol Energ Mat Sol C. 2009;93(6):1056-1061.

19. Miyajima S, Sawamura M, Yamada A, et al. Low temperature deposition of hydrogenated nanocrystalline cubic silicon carbide thin films by HWCVD and VHF-PECVD. Photovoltaic IEEE; 2006. p. 1604-1607.

20. Jannat A, Lee W, Akhtar MS, et al. Low cost sol-gel derived SiC-SiO2 nanocomposite as anti reflection layer for enhanced performance of crystalline silicon solar cells. Appl Surf Sci. 2016;369:545-551.

21. Künle M, Kaltenbach T, Löper $\mathrm{P}$, et al. Si-rich a-SiC:H thin films: Structural and optical transformations during thermal annealing. Thin Solid Films. 2010;519(1):151-157.

22. Tehrani FS, Badaruddin M, Rahbari R, et al. Low-pressure synthesis and characterization of multiphase $\mathrm{SiC}$ by HWCVD using $\mathrm{CH} 4 / \mathrm{SiH} 4$. Vacuum. 2012;86(8):1150-1154.

23. Scopel W, Fantini M, Alayo M, et al. Local order structure of a-SiOxNy: $\mathrm{H}$ grown by PECVD. Brazilian Journal of Physics. 2002;32(2a):366368 .

24. Pruthtikul R, Liewchirakorn P. Correlation between siloxane bond formation and oxygen transmission rate in TEOS xerogel. Journal of Metals Materials and Minerals. 2008;18(2):63-66.

25. King $\mathrm{S}, \mathrm{Chu} \mathrm{R}, \mathrm{Xu} \mathrm{G}$, et al. Intrinsic stress effect on fracture toughness of plasma enhanced chemical vapor deposited SiNx: H films. Thin Solid Films. 2010;518(17):4898-4907.

26. Perova T, Wasyluk J, Kukushkin S, et al. Micro-Raman Mapping of 3C-SiC Thin Films Grown by Solid-Gas Phase Epitaxy on Si (111). Nanoscale Res lett. 2010;5(9):1507-1511.

27. Lin S, Chen Z, Li L, et al. Effect of impurities on the Raman scattering of 6H-SiC crystals. Materials Research. 2012;15(6):833-836.

28. Leal G, Campos TMB, Sobrinho S, et al. Characterization of SiC thin films deposited by HiPIMS. Materials Research. 2014;17(2):472-476.

29. Liu M, Yang X, Gao Y, et al. Investigation of the damage behavior in CVD SiC irradiated with 70keV He ions by NEXAFS, Raman and TEM. Journal of the European Ceramic Society. 2017;37(4):1253-1259. 